\title{
NOVOS SUBESTÁGIOS DO CICLO DE MUDA DO CAMARÃO PALAEMONETES ARGENTINUS NOBILI,1901
}

\author{
Foguesatto, K. ${ }^{1,}{ }^{*}$; Nery, L.E.M. ${ }^{2} \&$ Souza, M.M. ${ }^{2}$ \\ ${ }^{1}$ Universidade Federal do Rio Grande (FURG), Programa de Pós-Graduação em Ciências Fisiológicas. \\ ${ }^{2}$ Universidade Federal do Rio Grande (FURG), Instituto de Ciências Biológicas. \\ *Autor correspondente: foguesatto.k02@gmail.com
}

Para crescer crustáceos necessitam trocar seu exoesqueleto por um novo e maior, este processo se desenvolve em um ciclo dividido em cinco estágios principais: intermuda (C), pré-muda (D), ecdise (E), pós-muda recente (A) e pós-muda tardia (B), além de subestágios que intercalam os estágios principais. Por exemplo, a Pré muda pode conter subestágios $\mathrm{D}_{0}, \mathrm{D}_{1}{ }^{\prime}, \mathrm{D}_{1}{ }^{\prime \prime}, \mathrm{D}_{1}{ }^{\prime \prime \prime}$ e $\mathrm{D}_{2}$, o mesmo pode ocorrer para os demais estágios, variando o grau de identificação entre as espécies. Para o camarão Palaemonetes argentinus Nobili,1901 já foram descritos os estágios $A, B, C$ e $D_{0-2}$; sabe-se que para outras espécies a pós-muda (B) ainda pode ser subdividida em $B_{1}$ e $B_{2}$. A identificação precisa do estágio de muda é substancial para estudos com crustáceos, uma vez que durante o ciclo ocorrem importantes mudanças morfológicas e fisiológicas. Neste trabalho caracterizamos dois subestágios de Pós muda (B) para P. argentinus. Os animais foram coletados no canal São Gonçalo, RS (32 07'13.8 "S 52³5'38.9" N), levados ao biotério aquático da FURG e mantidos em caixas com cascalho e 150 $\mathrm{L}$ de água doce, aeração constante, temperatura $\sim 23^{\circ} \mathrm{C}$, fotoperíodo de $12 / 12 \mathrm{~h}$ claro/escuro, alimentação $1 \mathrm{x}$ ao dia (ração para peixes Alcon Basic $(\mathbb{R})$. Identificamos os estágios através da setogênese, técnica que se baseia nas alterações morfológicas das cerdas/setas presentes nos apêndices, utilizando microscopia de luz (100x). Obsevamos os urópodes de 20 animais que foram acompanhados ao longo do ciclo. Em intermuda e pré-muda as estruturas das cerdas são compostas pelo cone setal, septo, nó setal e base setal; e os componentes do uropode são epiderme e matriz setal. Essas estruturas estavam presentes na intermuda e foram modificadas na pré-muda, ocorrendo a pigmentação da matriz setal. Na ecdise as cerdas antigas foram perdidas e na pós-muda recente (24 h após a muda) as estruturas das novas cerdas ainda não haviam se desenvolvido, estando preenchidas por um líquido (inclusões vesiculares - i.v). Observando a regressão das i.v em direção aos níveis onde os cones setais serão formados, identificamos o subestágio $B_{1}$ ( 48 h após a muda). O subestágio $B_{2}$ ( 72 h após a muda) foi identificado pelo espessamento da base setal, formação dos cones setais e do septo. Estas estruturas também são vistas na intermuda, portanto $B_{2}$ pode ser facilmente confundido, contudo nós percebemos que os cones setais ainda apresentam i.v e os septos são amarelados e de forma lobada. Assim $B_{2}$ é o último subestágio da Pós-muda tardia.

Palavras-chave: crustáceos, estágios de muda, identificação, setogênese. 